\title{
ETNOGRAFÍA
}

\section{MURUTAKARAPAN: DISEÑOS KUKAMA KUKAMIRIA}

\author{
Pablo Taricuarima Paima \\ Asociación Cultural Yrapakatun \\ contacto@pablotaricuarima.com \\ (1) https://orcid.org/0000-0001-7649-8034
}

\section{Resumen}

Esta es una investigación sobre las ceramistas kukamas cuyos antepasados se desplazaron durante la explotación cauchera al río Nanay. Es un estudio realizado en la comunidad Santo Tomás de los diseños en jarrones, vasijas, tinajas, ollas y su relación con la medicina tradicional.

Palabras claves: Kukama; Cerámica; Historia; Medicina tradicional

\section{Summary}

This is an investigation of the kukama ceramists whose ancestors migrated during the rubber boom to the Nanay River. This is a study conducted in the village of Santo Tomás of designs on pots, jars and vases and their relation to traditional medicine.

Keywords: Kukama; Ceramics; History; Traditional medicine 
La presente investigación considera a los ceramistas del pueblo kukama kukamiria culturas que se desplazaron de los afluentes del río Nanay, entre los años 1890 a 1936; poblaciones que migraron, en su mayoría, por la explotación cauchera en la Amazonía peruana.

Gracias a la conservación de esta actividad cultural; en la región Loreto en la actualidad, los kukama kukamiria han ganado merecido reconocimiento. La población de Santo Tomásjunto a Padre Cocha, comunidades del mismo origen, se constituyen en los conservadores y difusores de la producción artesanal en la ciudad de Iquitos, tanto del tallado en madera balsa, así como del tejido en fibras vegetales y la elaboración de cerámicas. La producción de cerámicas, principalmente, forma parte de las actividades más importantes que acompaña a su cultura, desde antes, durante y después del periodo de la migración (Tessmann 1998: 40-41).

Con esta investigación queremos reconocer el gran valor de esta práctica cultural kukama realizada en su gran mayoría por ancianos, y que gracias a ellos y su resistencia, pude hacer una reflexión sobre la identidad de mi pueblo natal y del propio autoreconocimiento de mi identidad indígena kukama kukamiria.

Analizaremos los testimonios de los ancianos ceramistas, valoraremos los conocimientos que ellos poseen, y que fueron representados a través de diseños plasmados en jarrones, vasijas, tinajas, ollas, etc. Conoceremos los procesos creativos y técnicos que desarrollan no solo los ancianos, sino también los nuevos ceramistas jóvenes; para compenetrarnos en su máxima expresión cultural. Lo haremos a través de relatos sobre los orígenes de los diseños que utilizan los ceramistas de Santo Tomás y aquella percepción animista espiritual que tienen con las plantas y greda del río.

Dentro de las técnicas que utilizan para pintar los diseños, tomaremos en cuenta los insumos hechos a base de las tierras de color extraídas de lugares y en tiempos muy específicos durante el año ${ }^{1} \mathrm{y}$ aquellos procedimientos que son respetados — según la creencia que tiene cada ceramistas - para lograr cierta durabilidad y consistencia cuando son expuestos a la candela y al humo en el proceso del quemado ${ }^{2}$.

1 La greda blanca y las tierras de color del río son extraídas y acumuladas en tiempo de vaciante de los ríos (julio a noviembre).

2 Etapa final de la cerámica después de haber pasado todo el proceso de elaboración, desde la extracción de la arcilla del río. 
Las tierras de color que son aplicados en la cerámica, también se utilizan para pintarse el cuerpo. ${ }^{3}$ Ambas prácticas fueron soportes que sirvieron para conservar todas las iconografías presentadas en este trabajo de recopilación. En los últimos años, la cerámica ha sido sometida a diversas influencias ${ }^{4}$ debido a la globalización que permite a los ceramistas el fácil acceso a referencias de otras imágenes de ceramistas de otras culturas; además, la oferta y demanda comercial, a bajo costo, de la artesanía por parte de los mercados artesanales de Iquitos, degeneró las cerámicas en técnica y acabado. La resistencia de los ceramistas para mantener sus procesos técnicos ancestrales se hace más difícil debido a la explotación desmedida de los recursos naturales y el mal manejo de los bosques tropicales por parte de algunos pobladores; además del desinterés de los gobiernos locales de turno por capacitar a las poblaciones ribereñas en el uso adecuado de estos recursos que se extinguen con rapidez; y con ello, los insumos que los ceramistas necesitan.

Lo que está por desaparecer no solo son los recursos naturales, sino también los diseños kukama kukamiria que se plasman en sus cerámicas, debido a la avanzada edad de los pocos ancianos que heredaron de sus ancestros estos conocimientos y el poco interés de los aprendices por continuarlos.

Los diseños de los ceramistas podrían conducirnos a interpretaciones acaso complejas, por los misterios desconocidos de esta cultura indígena, o también a generarnos interpretaciones sencillas cuando conozcamos sobre las actividades que desarrollan las personas de esta comunidad y las creencias que permanecen vivas hasta el día de hoy en los habitantes de Santo Tomás.

\section{Reseña de los kukama kukamiria que migraron hacia el río Nanay}

Los kukama kukamiria originalmente estuvieron ubicados a lo largo de los ríos Amazonas, Ucayali, Marañón, y afluentes de estos ríos (Tessmann 1998: 37). Los desplazamientos de los clanes kukama ${ }^{5}$ se deben a diversos factores ocasionados por episodios de explotación comercial del caucho y la extracción de otras materias primas (madera, piel de animales, carne de monte, etc.). También

$3 \quad$ Estas tierras de color son usadas para pintar el cuerpo en los concursos de danzas típicas en los colegios o en las comparsas de Mashakaras.

4 Tomamos como influencia directa a las capacitaciones que reciben los ceramistas kukama de Santo Tomáspor el municipio y la facilidad de ver otras referencias en el internet.

5 De vez en cuando, los kukama de Santo Tomásvisitan a sus familiares por los ríos Ucayali, Marañón y Amazonas: testimonio recogido de Martha Shauano (1968), el año 2014. 
debido a motivos religiosos 6 , y las epidemias desconocidas que arrasaron en ese entonces a los pueblos ribereños de la selva.

Los kukama, dirigidos por su líder sabio o anciano, se dirigieron inmediatamente hacia los lugares más próximos de sus comunidades, a las zonas aledañas o buscaron integrarse dentro de las pequeñas ciudades que empezaban a desarrollarse en el territorio amazónico entre los años 1880 a 1914. Las ciudades de Nauta, Iquitos y Manaos, fueron sedes de las primeras llegadas de estos migrantes que años más tarde, después de la explotación de la shiringa o jebe (caucho) decidieran ubicarse en las orillas de Morona cocha, río Nanay (testimonio recogido de Miguel Aquituari Ortiz [1947], en el año 2015). El deseo de alejarse de sus tierras nativas debido a estos sucesos, los llevó hasta tierras lejanas, como al país vecino de Brasil y Colombia, donde actualmente conviven con muchas colonias mestizas e indígenas ticunas. (Petesch 2003 110-115)

Desde una mirada general se podría decir que el conocimiento ancestral de los migrantes indígenas, como es el caso de los bora y yagua, que también fueron desplazados de sus tierras nativas hacia los afluentes del río Momón y Nanay, pudieron conservar sus prácticas culturales (ritos, fiestas, vestimenta, lengua, etc.) gracias al desplazamiento grupal de sus clanes. Asimismo, no podríamos asegurar que la cultura de los indígenas kukama se haya mantenido con más vitalidad en los grupos que no migraron y se quedaron en la zona de origen, debido al paso del tiempo, a ciertas presiones socioculturales y las interacciones constantes de los comerciantes citadinos que viajaban hacia estos pueblos con el propósito de obtener materia prima; a esto se suma la discriminación racial y menosprecio al considerarlos analfabetos e indígenas. Hasta ahora se pueden ver los problemas que generaron estas incidencias, como la autonegación de la identidad indígena kukama para aparentar ser como los demás y ser considerados ciudadanos normales.

\section{Los kukama kukamiria de Santo Tomás}

La comunidad de Santo Tomás se ubica a 16 kilómetros de la ciudad de Iquitos, en el distrito de San Juan Bautista, en la provincia de Maynas, región Loreto. No se sabe exactamente cuándo llegó don Tomás Huanaquiri, considerado por los abuelos el primer habitante de la zona donde se asienta actualmente la comunidad.

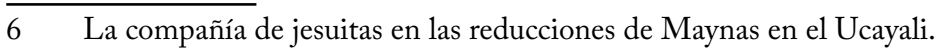


Después de la muerte de Huanaquiri, entre 1914 y 1918 llegaron en varias ocasiones el primer grupo de exploradores kukama: navegando desde Morona cocha por el río Nanay hacia sus afluentes, algunos provenientes del distrito de Parinari, San Pablo de Tipishca (río Marañón), según se pudo entrevistar a los pobladores más antiguos: doña María Luisa Cuacha Aquituari (1928), Guillermo Nimer Aricara Cuacha (1955) y María Juana Aquituari Macuyama (1932).

Los exploradores estaban liderados por Manuel Aricara (aproximadamente de 53 años), Juana Jaramillo (44 años) acompañado de sus hijos Juan Aricara (23 años), Guillermo Aricara (18 años), sus yernos Ulises Arirama (30 años), (esposo de Julia Aricara de17 años), Antonio Canayo (22 años) (esposo de Adelina Aricara de18 años) y Pablo Macuyama (20 años), (esposo de Vrígida Aricara de17 años). Las edades son aproximadas y definidas gracias a los testimonios de mis fuentes principales mencionadas líneas arriba.

Con el fin de explorar las tierras por el afluente del río Nanay, que desde un principio ofrecía abundancia de peces, (estaba lleno de mijanos (cardúmenes de peces desplazándose de un río a otro), sábalos grandes y chiquitos; "todos comíamos ahumando pango a cada rato, había muchos animales del monte: majas, sachavacas, venados" (María Luisa Cuacha Aquituari 2017). Había mucha miel de abeja por todos lados, y los antiguos abuelos decían en su lengua kukama: MapaTimatskuara ëmëtë chita (en este caño hay mucha miel de abeja) (Guillermo Nimer Aricara 2014).

Vieron las riquezas que la tierra producía, como evidencia estaba la chacra remontada del fallecido TomásHuanaquiri; decidieron asentarse en el lugar que todavía estaba poblado de algunos árboles frutales, guaba, anona, shinbillo, caña y piña, entre otras frutas regionales, a orillas de este caño.

Allí se establecieron las primeras familias de Manuel Aricara y su esposa Juana Jaramillo. Posterior a ellos y junto a los nietos de Manuel, empezaron a poblar el lugar otros familiares que vivían en la comunidad vecina de Santa Clara, Santa Rita y Lupuna: los Murayari, Maitahuari, Tina, Pacaya, Manuyama, Awanari, Tapullima y Taricuarima.

El anciano Gilberto Jaramillo Teco (1934) (testimonio recogido en el 2017) nos cuenta que antes todos vivían en Morona Cocha, pero hace mucho tiempo el gobierno les dijo que dejaran de vivir en ese lugar porque pertenecía al Estado (a la FAP). Algunas de las actividades para sobrevivir en este proceso de migración fueron la caza, recolección de frutas, pesca, la extracción de madera 
shungos para la construcción de casas, leña huacapurana, que en ese entonces eran comprados por los Freitas y Bustamante, las familias comerciantes del lugar.

La elaboración de cerámicas forma parte importante en la historia del pueblo kukama, pero no se conoce cómo surgió; si fue por la necesidad de tener utensilios para el uso diario en la comida y bebida o como elemento estético en sus fiestas. A este trabajo se habían encargado solo a las mujeres de cada familia. No hay datos de que los hombres hiciesen cerámicas, solo extraían la arcilla de la orilla del río, porque ellos tenían la responsabilidad de cultivar la chacra.

Es importante mencionar que en la etapa fundacional de la comunidad de Santo Tomas, entre los años 1914 a 1936, se hablaba de otras actividades artesanales: como la talla sobre raíces de los árboles, para formar figuras de animales con las raíces secas de los árboles de la orilla del río (Pablo Eli Taricuarima Pinedo, 1966, testimonio recogido en el 2017), el tejido en fibra vegetal de chambira y la elaboración de cerámica. Estas actividades se consagrarían años después de la fundación de su pueblo en 1936 por la demanda comercial de los compradores de la ciudad de Iquitos.

Producíamos lindos jarrones y tinajas con todas mis hijas, hacíamos sus dibujitos bien menuditos, igualitos y derechitos, sino, no nos compraban. A veces cuando no tenía diseños no querían comprar, y nos faltaba manos, mis hijos tenían que ayudarme, a sacar mucha greda y buscar leña para asar los trabajitos que hacíamos. (Maria Luisa Cuacha Aquituari 2014)

Conforme pasaron los años, el año 1936, en una asamblea comunal, decidieron fundar el pueblo con el nombre de Santo Tomás, incitados por foráneos que en ese momento visitaban el lugar con el propósito de predicar sus dogmas religiosos. Cumple un rol importante en este episodio el señor Oscar Saldaña y el Padre Miguel San Román Fernández ${ }^{7}$, quien en una de sus visitas fluviales a las nuevas comunidades asentadas a orillas del río Nanay, sugiere que se denomine Santo Tomás, en homenaje a Tomás Huanaquiri, el primer poblador kukama que vivió allí, sin considerar Timatsukuara o Mapaupatsu nombre que los primeros kukama habían denominado a la zona.

$7 \quad$ Sacerdote designado por la Iglesia católica para hacer giras fluviales a los nuevos pueblos conformados, con el fin de hacer casamientos y bautizos (Biografía Sacerdotes OSA, CETAIquitos) 
Esta situación podemos analizarla sobre la pre y post migración de los kukama de Santo Tomás, y discutir sobre el origen de negación a su propia cultura y cuáles fueron los motivos para que el pueblo aceptara con pronta facilidad las prácticas culturales provenientes de las ciudades occidentadas ${ }^{8}$ que a la vez determinaron la pérdida de su identidad indígena, acompañada del desinterés de los primeros habitantes de esta comunidad para dejar al olvido su lengua materna y sus tradiciones. Desde el momento en que decidieron renombrar a Timatsukuara y Mapaupatsu (caño donde hay miel) por Santo Tomás, se olvidó totalmente a Tomás Huanaquiri. Ahora, en las fiestas de celebración del aniversario cada año, el pueblo saca a pasear en andas por las calles principales al santo patrono español Tomás de Aquino.

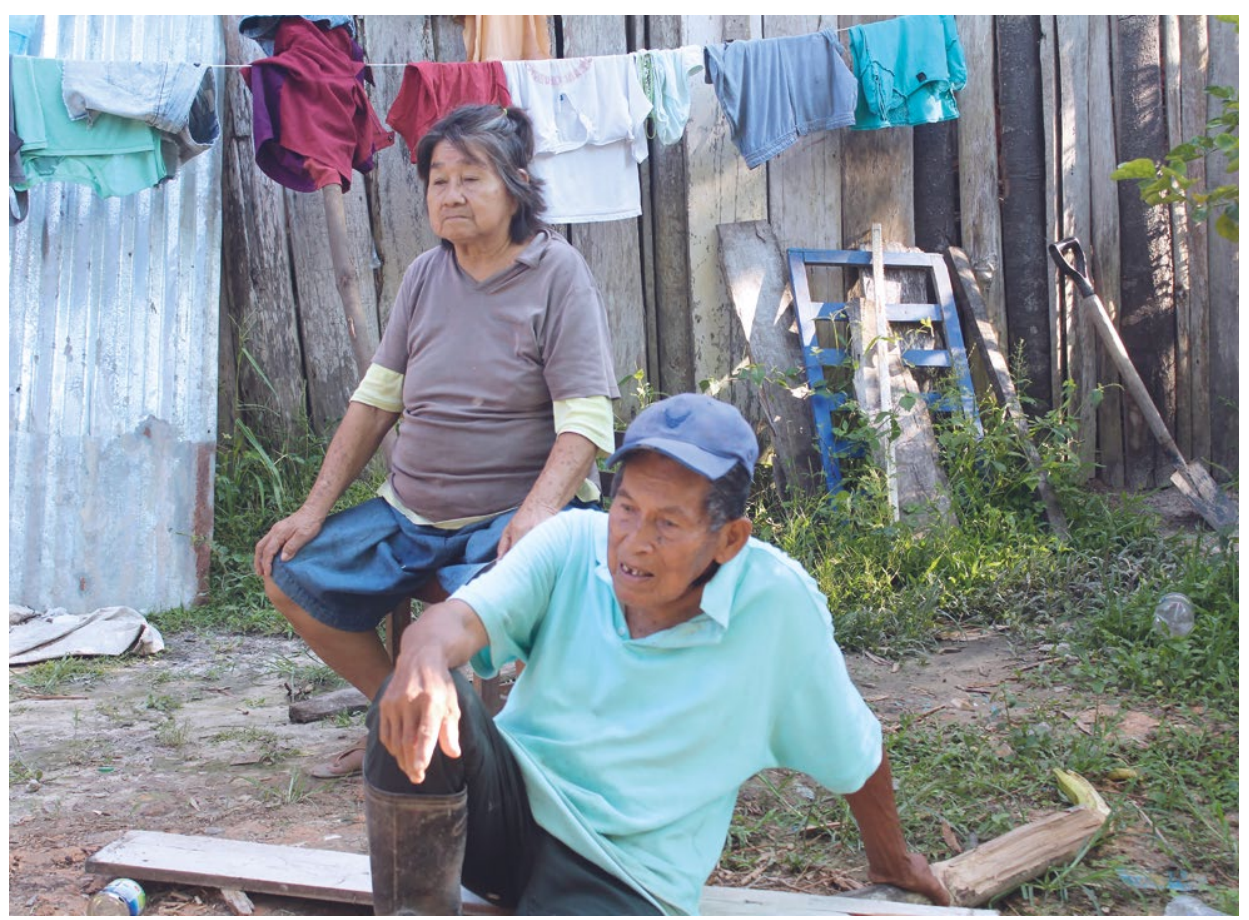

Casa de campo construida con materiales rústicos perteneciente a una familia de Portugal, está ubicada a orillas del río de Santo Tomás. Foto tomada por Pablo Taricuarima en 2017.

$8 \quad$ Palabra tomada de entrevista a Rember Yahuarcani en el documental Historias del Boom de Caucho (CAPV MINEDU- DIGEIBIRA, Lima 2017. 
Hoy en día, el pueblo de Santo Tomás comprende a los nietos de los migrantes kukama, quienes entienden la lengua de sus abuelos, pero no pueden hablarla debido a la falta de práctica. Este lugar también aloja a otros foráneos provenientes de diversos lugares del mundo, regiones costeras y andinas del país. Es promocionado por las autoridades municipales como un balneario turístico con fines de conglomerar visitantes para conocer y disfrutar la belleza natural de Santo Tomás. Pueblo que fuera un lugar seguro para los hijos de los kukama; quienes sin embargo, viven en reducidos espacios, uno al costado del otro, permitiendo a gente con poder económico y político que han construido suntuosas mansiones de lujo en amplios terrenos a orillas del Caño Mapacocha.

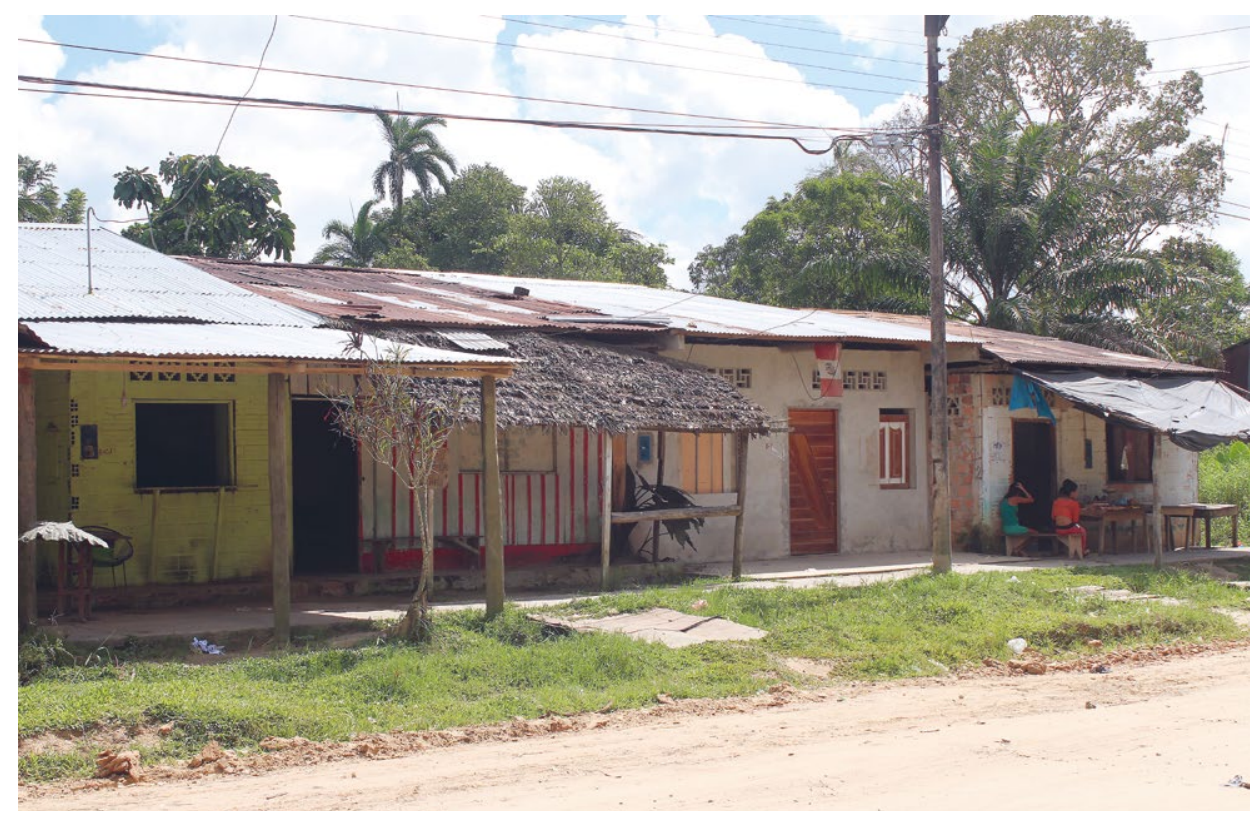

Casa de los pobladores de la comunidad de Santo Tomás. Foto tomada por Pablo Taricuarima en 2017.

En ese contexto, la reproducción cultural kukama enfrenta enormes desafíos para reconstruir los signos culturales y salvaguardar las tradiciones ancestrales que tratan de ser rescatadas por las iniciativas de la asociación Yrapakatun desde el año 2002. Labor apoyada por los jóvenes y ancianos sabios que se suman para reunir los testimonios para reconstruir el pasado que sostendrá el futuro de la 
cultura kukama. A través de este trabajo de investigación se logrará identificar aquellas fuentes más importantes para transmitir estos conocimientos a los niños que forjarán el futuro de Santo Tomás.

\section{Los diseños e iconografías sobre los jarrones, ollas y tinajas}

Los diseños de los jarrones, ollas y tinajas kukama, reflejan en sí la utilidad que tuvieron en las costumbres y celebración de fiestas en el pueblo de Santo Tomás. Siendo las principales referencias visuales los diseños que sus abuelas les enseñaron a partir de aquellas actividades en su vida cotidiana; como la siembra, la recolección de frutos silvestres, la caza nocturna, los viajes de varias semanas cuando iban de pesca, la construcción comunal de sus viviendas, etc. En todo momento eran de utilidad los objetos de cerámica, para transportar el masato, el agua y el aguardiente. Los diseños forman parte de la transmisión de conocimientos a través de la enseñanza de un conocedor; en este caso solo pudieron ser sus abuelas. Estas referencias visuales a partir de sus actividades, sirvieron solo para construir y adecuar sus diseños según la ocasión, los que fueron variando permanentemente.

Sin embargo, los motivos iconográficos que se dibujaban sobre cada cerámica fueron concebidos para embellecer sus objetos de uso cotidiano y utilizadas en las fiestas, pues representan sus creencias de los karuara, que son seres mágicos que habitan dentro del agua, en la tierra y las vivencias kukama. A través de dibujos geométricos, abstraídos, figurativos, ondulados, los kukamas nos transmiten su forma de entender el mundo desde su propia mirada.

\section{Los símbolos como medicina de los kukama kukamiria}

Los símbolos son reproducidos solo por algunos kukama de Santo Tomás, y son concebidos para algún fin medicinal o actividad temporal de sus ritos festivos. Los símbolos que son usados en el cuerpo, por ejemplo la planta de sachajergón rararaka, cuando el niño quiere ir a jugar en el bosque, la mamá o abuelita coge la planta sachajergón (la corteza de la planta tiene el parecido a la piel de la víbora jergón, considerada como una de las víboras más venenosas de la selva), esta planta sin ser arrancada del suelo se frota en los pies. De esta manera el niño va protegido a jugar en cualquier parte del monte, para cuando se encuentre con la víbora, esta pueda sentir el olor de la curación y se aleje del lugar. 


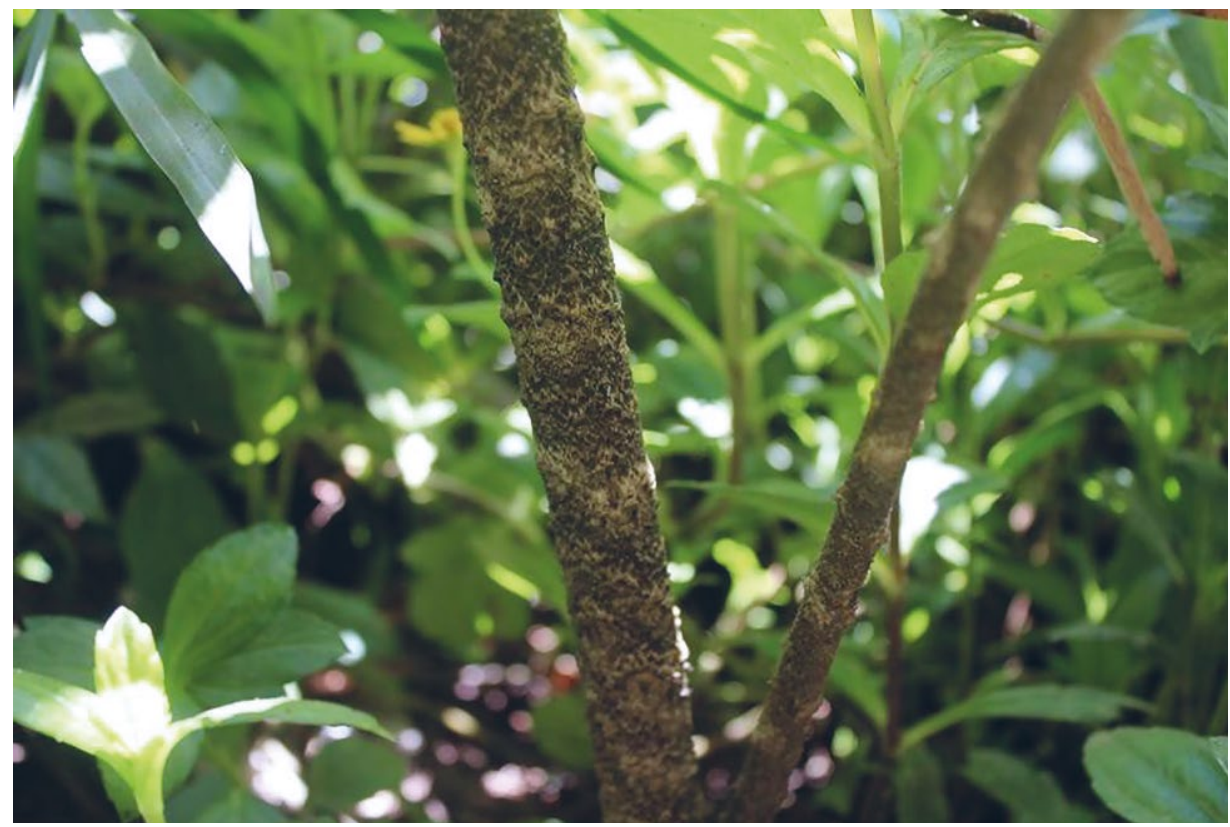

Planta sachajergón rararaka. Foto tomada por Pablo Taricuarima en 2017.

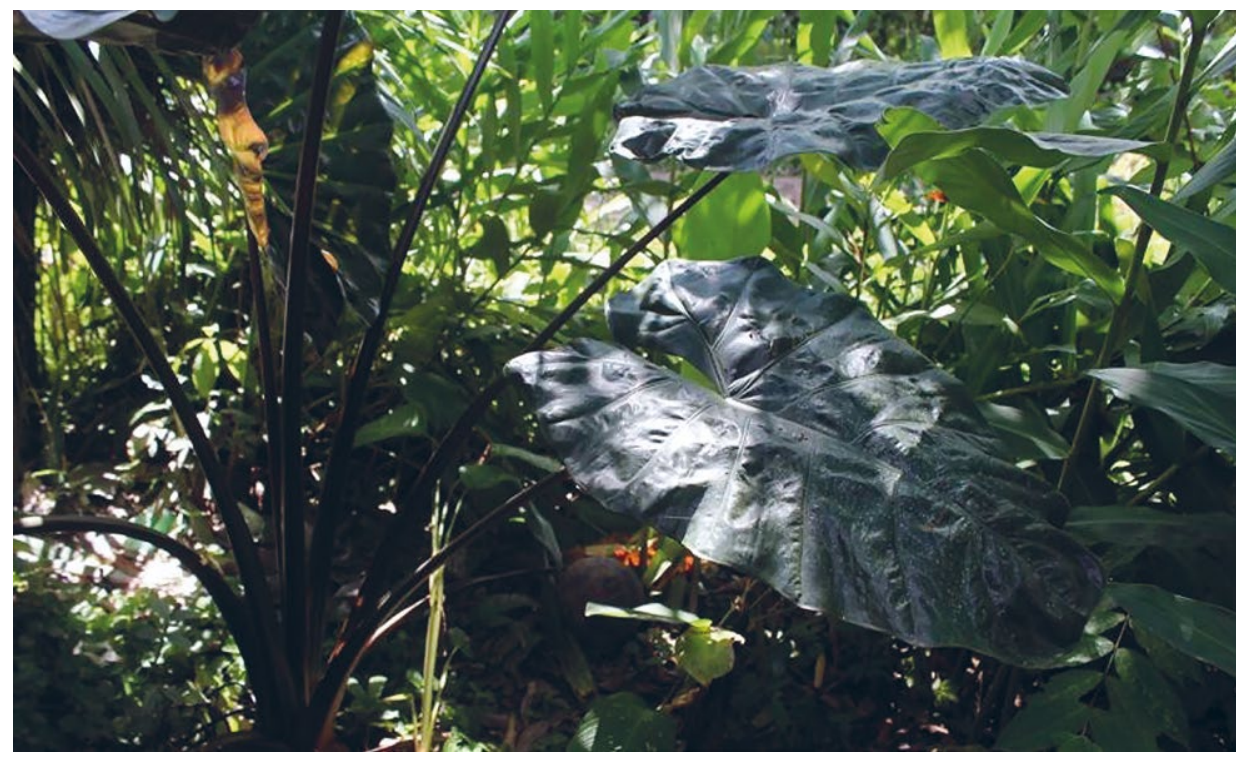

Planta patikina negra. Foto tomada por Pablo Taricuarima en 2017. 
Los símbolos evidentemente están relacionados con las plantas medicinales. Muchas de ellas son usadas para proteger las casas de los pobladores; por ejemplo, las patikinas negras, son sembradas en las esquinas de las casas, y según sus creencias, cumplen un rol de ser guardianes ante la ausencia del dueño de la casa. También existen patikinas de otra coloración, que solo son usadas para decorar los patios de las casas.

Así como la patikina negra, hay otras plantas que por sus características de flotar sobre el agua los kukama la denominan putuputu (palabra kukama que significa planta que flota). Esta, en particular, es utilizado para hacer brujería (hacer daño a una persona). Algunos payun (brujo malo) mandan a arrancar en secreto estas plantas a su aprendiz a veces para dañar al dueño de la casa que fue extraída o para alguna otra persona, y el payun se encarga de darle una lección. En algunos casos, estas brujerías pueden matar a las personas.

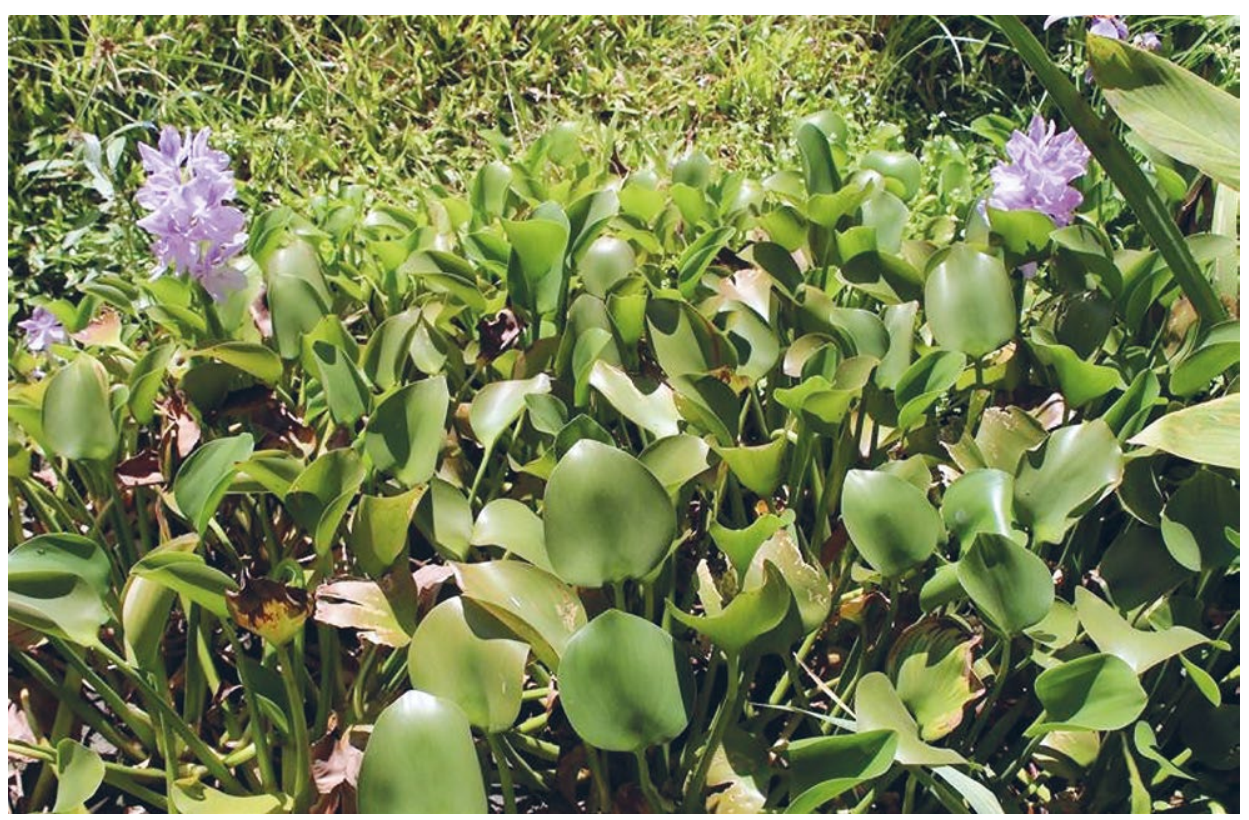

Planta putuputu floreciendo. Foto tomada por Pablo Taricuarima en 2017.

En el caso de los diseños creados a partir de estas plantas medicinales, las dibujan con la forma de estas plantas. Al momento de crearlas están pensando en lo que significa y lo que va a proteger o hacer. De esta manera, este símbolo es viviente en cada kukama. 


\section{La cerámica kukama kukamiria de la comunidad de Santo Tomás}

Al hablar de la cerámica kukama de la comunidad de Santo Tomás distinguiremos entre las elaboradas por los ceramistas antiguos y los ceramistas jóvenes que aprendieron de los ceramistas antiguos, para adecuarlas a técnicas modernas y vanguardistas. Como resultado de esta adaptación se empezaron a producir objetos con acabados más simples, con la intención de satisfacer un mercado que acostumbró a pagar muy poco por las cerámicas. Se puede percibir que muchas de las cerámicas no tienen diseños de iconografías originales, y son copiados de otros diseños de culturas andinas y costeñas solo por el gusto del cliente (Alejandro Canayo Aricara 1936).

Durante las últimas décadas, la cerámica kukama de Santo Tomás ha experimentado cambios a diferencia de las que se hacían antes. Los ceramistas usan nuevas herramientas y tecnologías para su elaboración, y mucho del conocimiento tradicional se ha reemplazado por procesos de fácil elaboración ${ }^{9}$. Para diferenciar los tipos de cerámica, es necesario observar con detenimiento no solo la densidad, coloración y el peso de cada cerámica. Lo que determina realmente la diferencia es la aplicación de iconografías sobre la superficie, porque solo los antiguos ceramistas las conocen y las pueden hacer; así como llegar a conocer la iconografía kukama y diferenciarla de otras culturas; por ejemplo de la iconografía shipibo-konibo que también es una cultura ceramista que utiliza iconografías sobre sus cerámicas. En muchos casos, se puede ver que por una demanda comercial, los ceramistas jóvenes de Santo Tomás copian diseños y modelos de objetos precolombinos costeños y andinos, solo por demanda comercial.

En un primer momento, si quisiéramos clasificar y decir cuál es la verdadera cerámica kukama kukamiria en Santo Tomás y diferenciarlos por la calidad técnica y el acabado, evidentemente hay cerámicas que tienen un excelente trabajo manual, simétrico, pulcro, con trazos más exactos, pesos livianos, y muchos detalles que podríamos considerar a este tipo de cerámicas como la verdadera de esta comunidad. Aun separándolas de las que fueron hechas con ayuda de alguna herramienta moderna, se sabe en todo momento cuál de los objetos son más originales y manuales que otros; pues no es así, y podríamos equivocarnos si los clasificamos de esta manera, que nos alejaría de una verdadera pieza kukama.

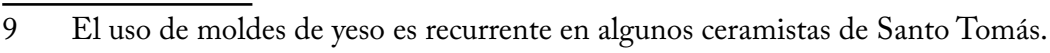


Sin embargo, para ahondar nuestra exploración y comprender los procesos técnicos, artísticos y espirituales que requiere la elaboración de la cerámica kukama, tuvimos que acudir a los mismos ancianos y jóvenes ceramistas, quienes compartieron los conocimientos heredados de sus antepasados.

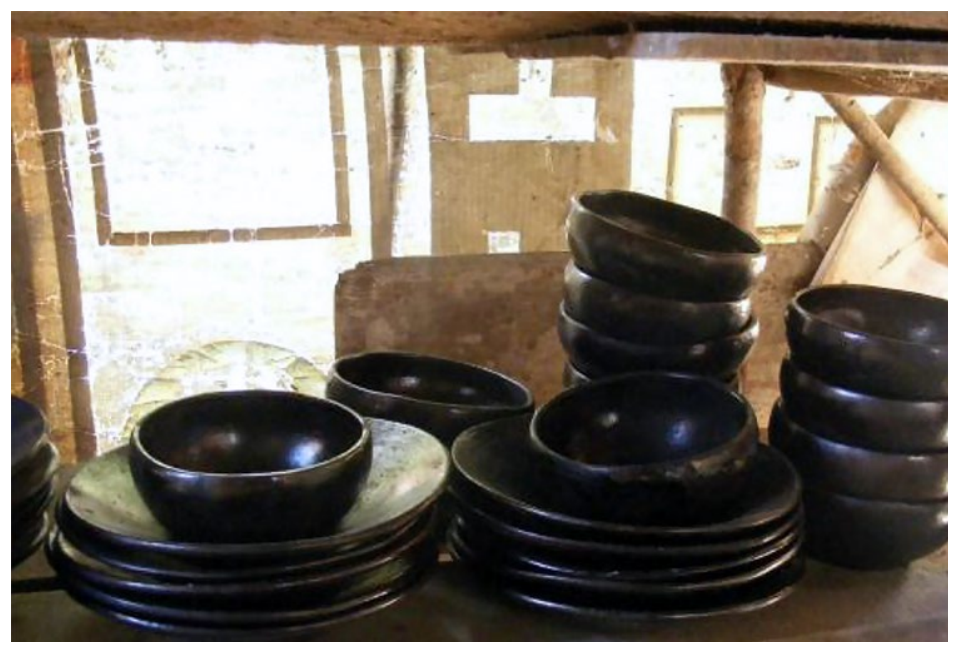

Platos y ensaladeras con la técnica de cerámica negra realizada por la ceramista Lidia Canayo. Foto tomada por Pablo Taricuarima en 2013.

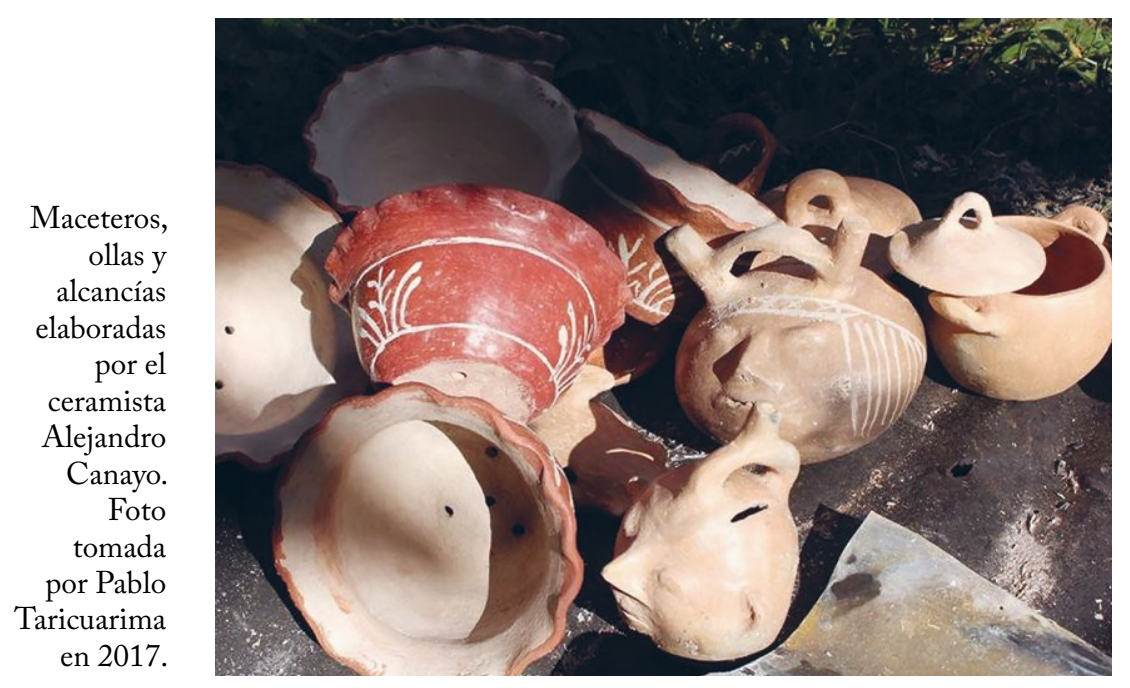




\section{Amazonía Peruana}

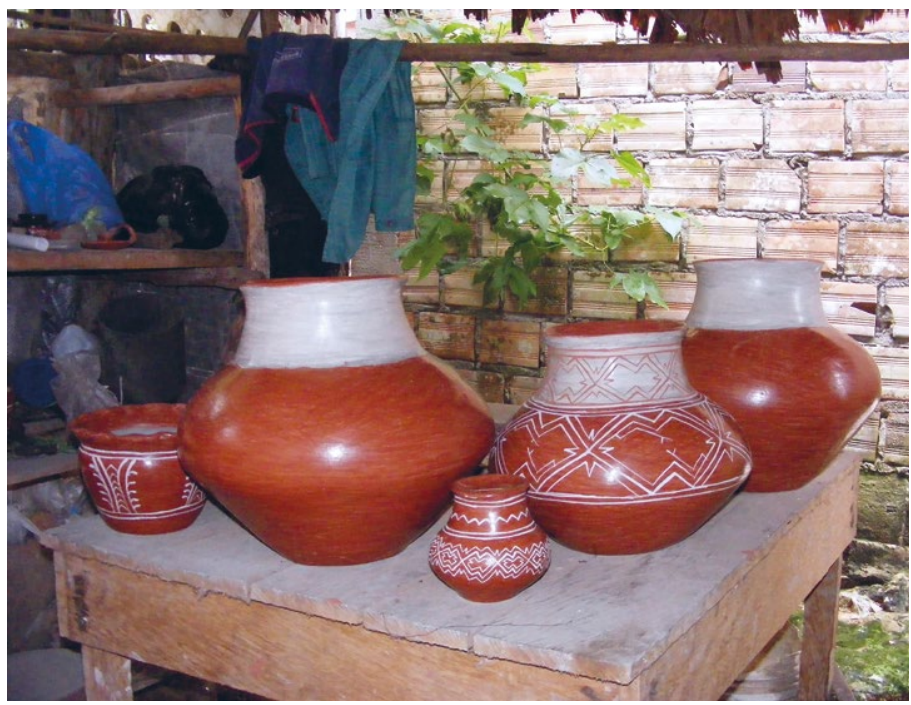

Jarrones para guardar el masato y agua, elaborado por la ceramista Lidia Canayo Aricara. Foto tomada por Pablo Taricuarima, 2013.

tradicional para guardar agua y masato, realizado por el ceramista Alejandro Canayo Aricara. Foto tomada por Pablo

Taricuarima, 2016.

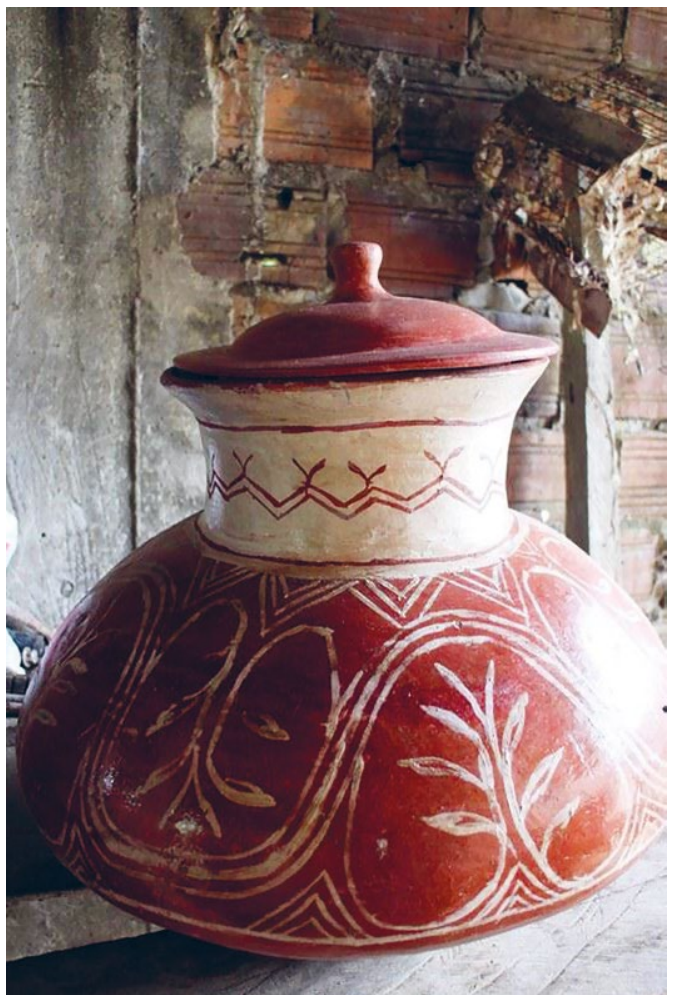


En el año 2013 entrevisté a María Luisa Cuacha Aquituari (1928) quien además de ser ceramista, es partera de las madres kukama y se dedica a sacar el manchari (susto) de los niños de la comunidad de Santo Tomás. Ella es viuda de Guillermo Aricara Jaramillo, hijo del líder kukama Manuel Aricara, y uno de los fundadores de Santo Tomás. Doña Luisa, nos explica cómo elaboraba la cerámica que le enseñó su mamá y su abuela:

Esperamos que termine la creciente del río, se cava un metro de profundidad a veces más, para sacar la greda más limpia de arena y raíces. Tienes que tener bien limpias las manos; no debes tocar sal y azúcar, nada de la cocina, no debes estar menstruando, porque el barro es bien celoso, si no sigues las indicaciones, la cerámica se reventará en la candela, cuando lo tengas que quemar. (María Luisa Cuacha. Testimonio recogido en 2013)

La compenetración de los ceramistas con la greda es en un grado de total respeto y si no mantienen las recomendaciones de los sabios, no podrán ser buenos ceramistas y tendrían que dedicarse a otras actividades para sustentar su vida diaria. Además, para conseguir el barro adecuado tienen procedimientos, tal como lo dijo el antepasado.

En otra oportunidad pude conversar con María Juana Aquituari Macuyama (1928), una ceramista anciana de la comunidad — quien además de ser nuera de Ulises Arirama, uno de los primeros exploradores kukama que vino con Manuel Aricara- nos describe las herramientas que usaba para pintar sus iconografías y realizar su cerámica:

Se corta el cuÿa (calabaza amazónica que también es denominada wingo o pate). De la cáscara se hace piruta (cuñas para formar la cerámicas) de diferentes tamaños que también sirve para cortar el barro y darle la forma que se quiere. Y para pulir utilizamos ÿuwata, una piedra de color negro que conseguimos de las orillas del río... Para conseguir que los trabajos duren utilizamos las cenizas de la corteza de un árbol llamado itakipi o apacharama, lo mezclamos con la greda blanca que sacamos del río. (Juana Aquituari. Testimonio recogido en 2012)

Los procedimientos para la elaboración de la cerámica, los insumos y materiales que utiliza Juana también es usado por los demás ceramistas desde mucho antes que vinieran a Santo Tomás. Son objetos rústicos hechos por sus abuelos y ellos mismos.

E1 2013 invitaron a los ceramistas a participar de unos talleres con el fin de mejorar sus técnicas dictado por un maestro ceramista traído de ChulucanasPiura. Participaron algunos interesados solo los días que podían. Durante ese 
periodo el municipio distrital me solicitó que le proporcionara el primer boceto de recopilación de iconografías, que fueron utilizados en esa capacitación.

Era la primera vez que los ceramistas de Santo Tomás socializaban las iconografías, que en su gran mayoría, eran los diseños recopilados de la ceramista Lidia Canayo Aricara (1936) cuyas características de trabajo se diferencian de los demás ceramistas.

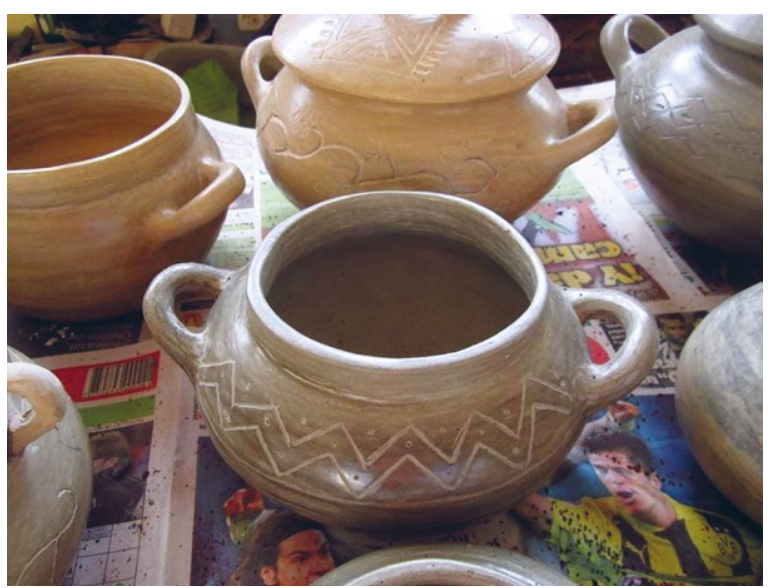

Cerámicas elaboradas por los ceramistas de Santo Tomás durante la capacitación del maestro ceramista de Chulucanas-Piura, en el año 2013. Foto tomada por Pablo Taricuarima, 2013.

Esta labor se complementa con el apoyo de su esposo Tina Manuyama (1928) hijo de Ángel Tina Canayo (1964). Ellos me cuentan que se toman el tiempo necesario para hacer un buen trabajo y se demoran el tiempo que tiene que ser, porque les gusta hacer un buen trabajo:

Yo siempre hago mis propias herramientas para hacer mi cerámica. Amaso el barro, le mezclo con las cenizas de la apacharama. Hago las tripitas (tiras de barro de 40 o $50 \mathrm{~cm}$.) y con eso voy formando el diseño que quiero colocando una sobre otras circularmente sin dejar aire. Se puede hacer la forma que uno quiere, por ejemplo: yucuchi (ollas), muritsu (tinajas). Después, cuando se termina de formar, las pongo a secar al sol dos días hasta que la cerámica tenga color blanco. Y ahí viene el pulido con mi piedra, y una vez que está bien lijadita recién me pongo a pintar las iconografías con el tipiro (pincel rígido hecho de madera). Los hago de uno en uno con mi paciencia para luego quemarlos en un shunto de wakapurana fresca (montículo piramidal de cortezas de árboles de wacapurana). (Lidia Canayo. Testimonio recogido en 2012)

Con Lidia, su esposo y su hijo, pude recopilar la mayoría de los diseños que presento en esta investigación. Así como ellos, otros ceramistas han conservado este conocimiento. Entre ellos están la señora Juana Arirama (1942) y su esposo 
Alejandro Canayo Aricara (1936), Venancio Yuyarima (1948) y su esposa Matilde Arirama (1947),y el más joven, Felipe Canayo Arirama (1974) con sus hermanos Rusber Canayo (1980) y Deysy Canayo (1983).

El más activo de los hermanos Canayo es Felipe, quien tiene dos décadas de trayectoria haciendo la cerámica en la comunidad. Trabaja de la misma forma que sus padres y abuelos, el modelado con tripitas. Desde hace 6 años empezó a usar moldes de yeso y de la misma greda. Felipe se está especializando en la producción de cerámica negra, me cuenta que a pesar de que la elaboración de la cerámica negra es más difícil que las de color, él prefiere seguir haciendo las negras, porque las vende con más rapidez.

Felipe nos explica el proceso del quemado de la cerámica negra:

Cuando se hace el shunto, tiene que ser de madera fresca, no tiene que arder demasiado. Se le coloca en un tiempo aproximado de 30 minutos a la exposición de la candela. Tengo que estar observando y dejarlo el tiempo que tiene que ser, porque si le saco antes, no se negrea y si le saco después del tiempo, se blanquea. (Testimonio recogido en el año 2017)

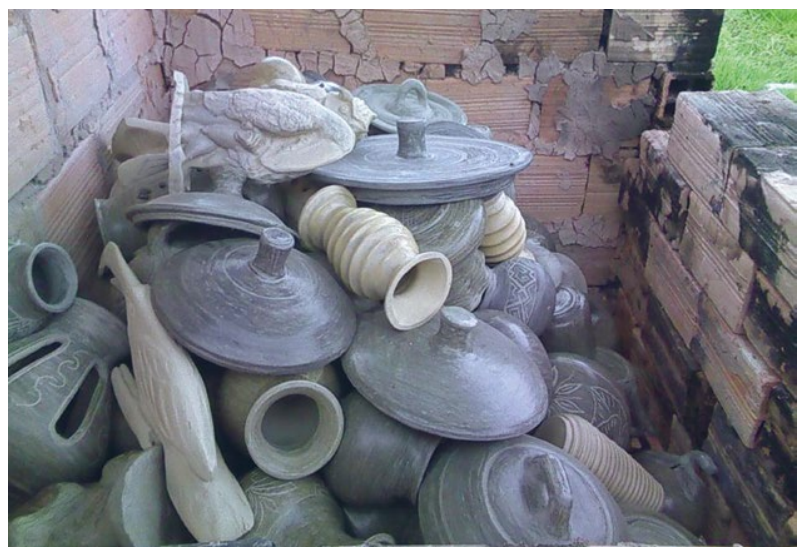

Cerámicas elaboradas por los ceramistas de Santo Tomásdurante la capacitación del maestro ceramista de ChulucanasPiura, en el año 2013, listas para ser quemadas en un horno de ladrillo. Foto tomada por Pablo Taricuarima, 2013.

La producción de la cerámica kukama en todas sus variedades es a través de la experiencia y conocimientos obtenidos por el interés de cada ceramista. Como Felipe, quien nos dice que aprendió el trabajo de la cerámica mirando a su papá desde que era muy niño. Ahora conoce a detalle el proceso que es literalmente hecho por sus manos. Muchos de estos conocimientos fueron heredados de los ceramistas ancianos; así como Juana Aquituari, Luisa Cuacha, Teolinda Manihuari y otras ancianas que conservan los conocimientos intactos. Todas aprendieron de sus abuelas. Las tres ancianas que aún viven en Santo Tomás, 
tienen entre 90 a 94 años. Me cuentan con tristeza en sus rostros que debido a su avanzada edad, ya no podrán hacer más cerámicas en su vida. Sin embargo, sus conocimientos están vivos y listos para enseñar a los que desean aprender.

Hasta ahora hemos podido analizar las técnicas y procesos de elaboración de la cerámica kukama de la comunidad de Santo Tomás; conocer los testimonios de los principales actores en este valioso trabajo; comprender brevemente los diseños que plasman en la cerámica, elaborados desde sus propias creencias y símbolos que conservan hasta el día de hoy.

La migración forzada desde sus tierras originales hacia las ciudades, afectó el desarrollo natural de su producción, cuando empezaron a depender de la venta de sus cerámicas para subsistir en su vida diaria, reemplazando muchas veces el verdadero sentir que ellos tenían al hacer una $\ddot{u} u c u c h i$ o muritsu, que inicialmente tenía un propósito de utilidad en la casa, para luego ser de interés de las personas de la ciudad. Luisa aún recuerda que tenían que caminar muchas horas desde su comunidad a la ciudad de Iquitos, cargando sobre sus espaldas sus cerámicas al interior de una sábana. Las vendían en las calles como vendedoras ambulantes; y cuando terminaban de vender todos sus productos, con ese dinero compraban arroz, azúcar, sal y kerosene (testimonio recogido en el año 2017).

Cuando fundaron la comunidad de Santo Tomás, no había la necesidad de vender y comprar entre ellos, todo lo que se producía era para compartir entre todos, excepto los productos que tenían que vender en la ciudad (leña, cerámica) existía una gran afinidad en todos los sentidos: hablaban la misma lengua, algunos eran bilingües (castellano y kukama), habían pasado una etapa difícil de explotación con los caucheros, se ubicaron en Morona cocha en una propiedad de las fuerzas armadas y tiempos después fueron desplazados nuevamente. En ese entonces las tierras del río Nanay estaban concesionadas por la familia Freitas, quienes vieron que la reubicación no afectaría su negocio. Así que los kukamas exploradores emprendieron la búsqueda de las tierras para conformar las actuales comunidades: Santo Tomás, Santa Clara, Santa Rita, Lupuna, etc.

El tema de revalorar los conocimientos y procesos creativos de los ceramistas forma parte de una de las tareas emprendidas por la asociación Yrapakatun. La lengua kukama estaba en un proceso de extinción debido al desinterés de los mismos kukama por no valorar lo suyo. Sin embargo, en estos últimos años, existen iniciativas de algunas instituciones culturales y del Estado por reconocer y salvaguardar las culturas amazónicas. Dentro de esta 
labor, el MINEDU-DIGEIBIRA empezó la normalización de las 47 lenguas de la zona amazónica, a través de talleres junto a especialistas, lingüistas y los sabios hablantes de su lengua original.

Además, gracias al fácil acceso debido a las redes sociales (Facebook, WhatsApp, Youtube), en el caso de la cultura kukama, se puede intercambiar información de textos y videos de acciones que se realizan en otros países como Brasil y Colombia.

\section{Una aproximación a los testimonios del origen de los diseños kukama a través de la cola de la Puraua}

Cuando empecé mi investigación sobre los diseños iconográficos de la cultura kukama entre los años 2009 y 2017, fue una decisión que se originó después de un viaje a la ciudad de Lima en el año 2007. Al estar lejos de Santo Tomás, reflexioné y recordé todas las vivencias de mi pueblo y las cerámicas que había visto en mi niñez. Tuve la oportunidad de regresar a mi pueblo, y desde entonces inicié esta labor de entrevistar a los sabios ancianos, encontrando maravillosos relatos escondidos en sus memorias.

El relato de la cola de la puraua se relaciona con el origen de los diseños kukamas ${ }^{10}$ contado por el sabio Pablo Eli Taricuarima Pinedo (1966). El relato se lo contó su fenecido padre Purificación Taricuarima Cahuaza (1915), a través de esta historia empezaremos a desglosar el principio de la cosmovisión kukama.

Antes vivíamos muy cerca de las orillas del río, cuando mis abuelas ceramistas necesitaban los dibujos para pintar sobre sus ollas de barro, mi abuelo soplaba su mapacho para levantar sobre el río una cola gigante de la puraua, y de allí en la parte de debajo de la cola copiaban todos los diseños que necesitaban. (Testimonio recogido por Pablo Eli Taricuarima Pinedo en 1966)

Podemos entender la respuesta a nuestra pregunta sobre las formas y dibujos que utilizaban las antiguas artesanas para pintar las cerámicas, copiadas de las líneas que lleva la puraua en su cola.

Cada una de las líneas tienen sus propios nombres, por ejemplo, las más gruesas se llaman tuan y las más delgadas miminiun. En su gran mayoría están relacionadas con otras, parten de alguna estructura matriz y se van reconstruyendo entre sí. Por ejemplo, la figura10.

10 La puraua es una creencia kukama que describe a una inmensa boa, fiera que representa a la madre de los ríos. 


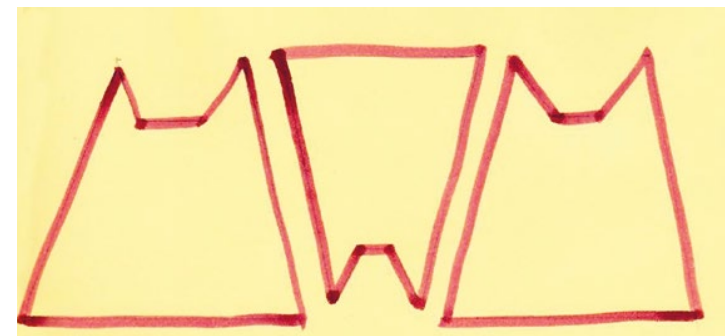

Fig 10 Mui, diseño de cabeza de víbora mala, 2011. Diseño recopilado del libro de Girard, 2011.

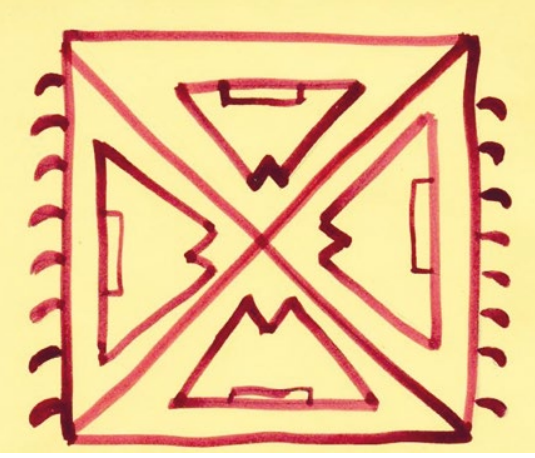

Fig. 20 Kuarachi tupa kuara, casa de la gran luz del sol. Recopilada del libro de Girard, 2011.

La figura 10 es un elemento recopilado por Girard en 1958, y es utilizado para construir la figura 20.

Ambas figuras significan elementos diferentes de la naturaleza: un astro y un animal terrestre; uno considerado por la cosmovisión kukama como un ser que vive en el quinto mundo y el otro vive en el segundo, tal vez tenga relación con la Mui Watsu de la figura 30.

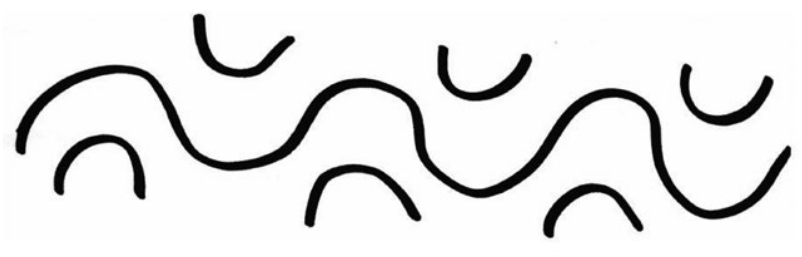

Fig 30 Mui Watsu, la gran boa. Recopilada de Pablo Eli

Taricuarima el 2014. 
Otras son marcas muy parecidas a las marcas de la boa en su cabeza y otras representan la luz máxima que viene a ser el día o, literalmente, el sol. Del mismo modo la figura 18 y la figura 21.

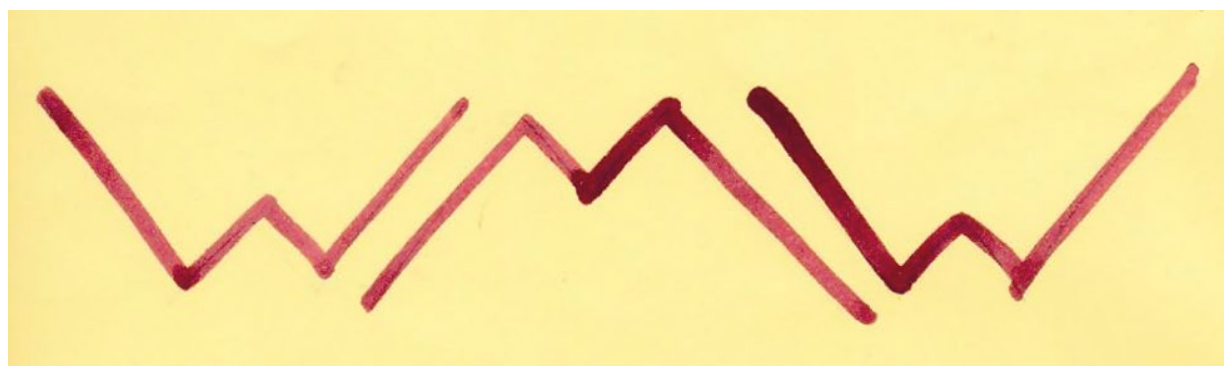

Fig 18. Tsawa kana, señales para pintar el cuerpo del hombre. Recopilada de Lidia Canayo el año 2010.

Fig. 21 Mutsana, medicina de la vida. Recopilada de Lidia Canayo el año 2010.

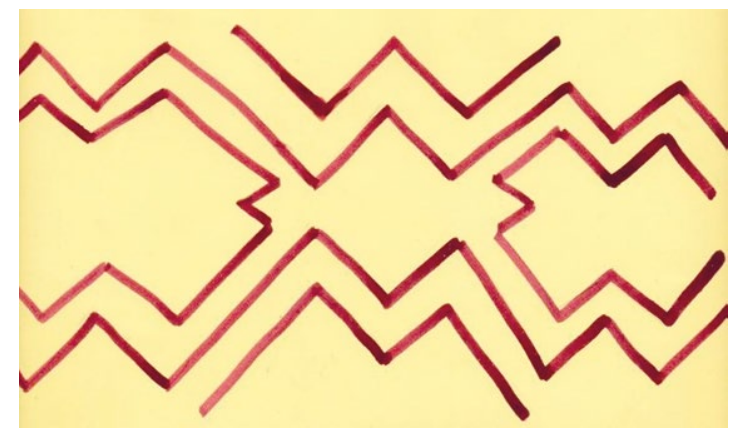

Tienen líneas transversales de abajo hacia arriba y al revés, que separadas o interpuestas, son muy parecidas. Las iconografías tienen combinaciones geométricas estilizadas y otras figuras reconocibles. Tal es el caso de los nombres que lleva las iconografías (véase la fig. 6 cuyo nombre Nanu significa en castellano, piña).

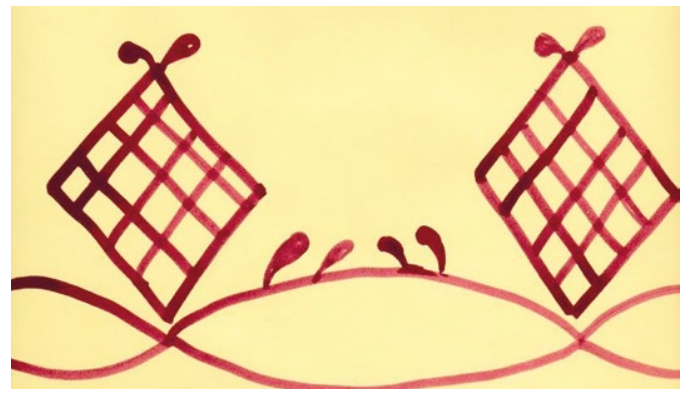

Fig. 6 Nanu tuan, sembrío de piñas grandes.

Recopilada de Lidia

Canayo el año 2008. 
Asimismo, la figura 2 y su mismo nombre, Parana pura, habla del río, y la figura representa al río.

Fig. 2 Parana puna, exaltación de los ríos y las orillas. Recopilada de Lidia Canayo

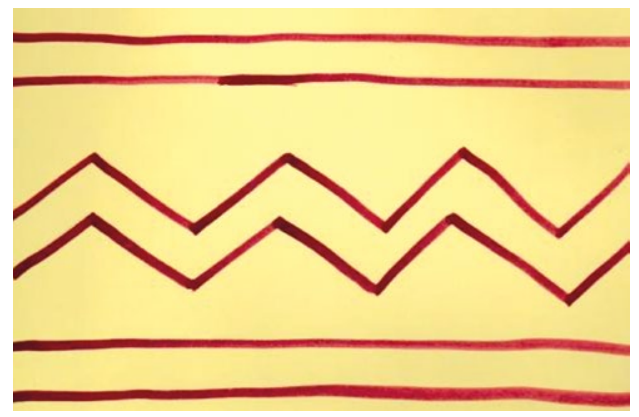
en el año 2008.

Cuando conversamos con los ancianos ceramistas kukama de Santo Tomás, que vienen a ser nietos de los abuelos antiguos; ninguno de ellos sabía los nombres y significados de los diseños que hacían en sus cerámicas. Sin embargo, los siguen haciendo sobre sus trabajos.

Los ancianos se refieren a la boa como un ser importante y protector más que cualquier otro animal del agua; esto tiene mucha relación con el segundo relato narrado por Nímer Aricara Cuacha (1951), sabio fallecido en el año 2014 en la comunidad de Santo Tomás.

Cuando alguien desaparecía en los ríos de la selva, los abuelos ikaraban el agua (cantos chamánicos) y salía una cabeza de una fiera gigante de color negro, tenía ojos muy pequeños y el tamaño era como una casa grande. En su cabeza tenía muchos dibujos de colores, y podíamos ver a la persona que se había perdido hace muchas semanas, salir de su garganta. (Nímer Aricara. Testimonio recogido en 2011)

Asimismo, la abuela Luisa nos cuenta que su abuela Celendonia Aquituari (1890 aproximadamente) le decía que los diseños que hace en sus cerámicas los sacaba de sus ikaros y cantos medicinales. Así también los copiaba de las puwatsakana kuara (sogas del interior de la selva), y de los sembríos de sus chacras de piña. Por ello, inicialmente nos da a entender que las iconografías y símbolos kukama representan figuras y elementos que veían también a su alrededor. Pero nos preguntamos ¿cuál es el criterio para seleccionarlos? También algunas iconografías representan a las plantas sagradas, como la puwatsa y pekuara kana, que hablan de plantas que habitan fuera y dentro del agua. También representan a los espíritus de los chamanes y de las personas después de la muerte. 


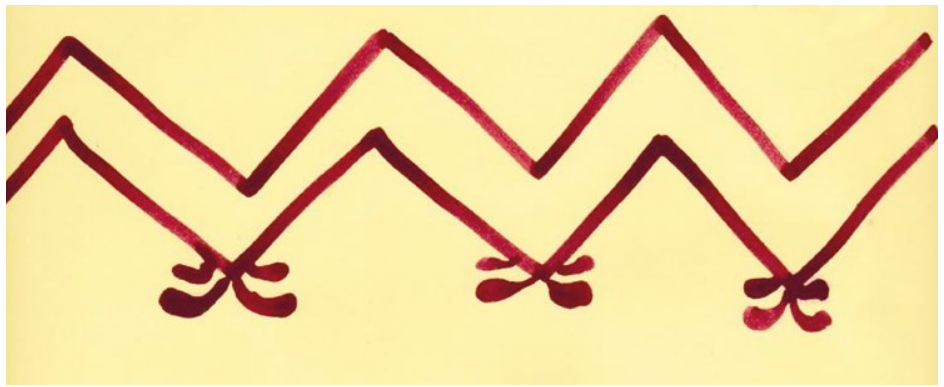

Pekuara kana, plantas que viven dentro de los lagos. Recopilada de Lidia Canayo el año 2008.

Aunimama, madre de los ríos. Recopiladas de Pablo Eli Taricuarima el año 2014.
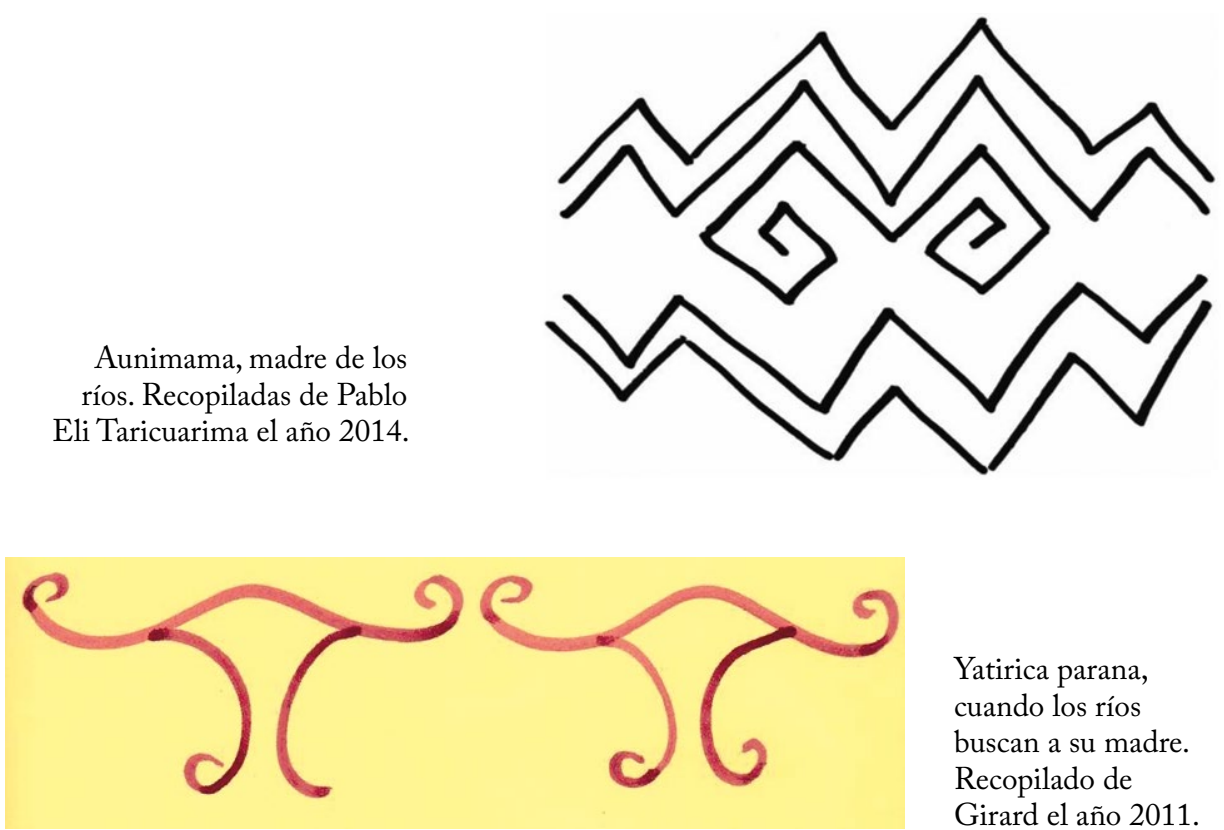

Yatirica parana, cuando los ríos buscan a su madre. Recopilado de Girard el año 2011.

Hay un gran significado detrás de cada diseño. Unas hablan de la maternidad, otras de la vida y lo que representa para los kukama, de su vínculo con la naturaleza, los espíritus de las plantas, sus creencias sobre los astros y la devoción a los grandes poderes sobre los cielos y bajo el agua. También está presente el hombre a través de sus quehaceres con sus chacras y viviendas. Es decir, todo lo que pudo haber existido en relación a su propia existencia.

El análisis de la iconografía y simbología kukama kukamiria nos lleva a conocer parte de un lenguaje más amplio, que hasta cierto punto quisiera que se quedara en el misterio, y de esta manera no perdería el valor que tuvo cuando 
su dueño lo transmitió al antiguo kukama en algún paraje de las profundidades del agua y los montes de la selva.

A partir de esta situación, e inspirado en mis abuelos que ya fenecieron, quiero dar a conocer los nombres de las iconografías y símbolos, del cual tuvimos que realizar un consenso. La primera reunión fue en el año 2010, entre algunos de los ceramistas antiguos y sabios conocedores de la cultura y la segunda reunión fue para aprobar la publicación de esta investigación. Nos reunimos el día viernes 16 de junio a horas 16: 00 p.m. del año 2017, junto a los ceramistas antiguos Juana Aquituari Macuyama y María Luisa Cuacha Aquituari, los sabios ancianos Leonidas Arirama Yahuarcani,(1938) Miguel Aquituari Ortiz, Humberto Jaramillo Aquituari (1943), Pablo Eli Taricuarima Pinedo, Oscar Aricara Manuyama (1944) y Pascual Aquituari Fachin, en las instalaciones de la Gran Kukamera ubicada en la calle Venecia S/N, de la Asociación Cutural Yrapakatun, con el fin de llegar a una aproximación de lo que se podría considerar como los diseños verdaderos en su correcta escritura y denominación. Finalmente, prefiero pensar que los verdaderos dueños del significado y los conocimientos de estos símbolos e iconografías, que compartieron los antiguos ceramistas, regresaron al lugar de donde estuvieron originalmente, debajo de la tierra, debajo del agua, en los montes, en el aire, en los cielos, guardados en la barriga, la cola y la cabeza de la Puraua.

\section{Referencias bibliográficas}

Girard, Rafael. Indios selváticos de la Amazonia peruana. Libromax editores, 1958.

Petesch, Natalie. "Los Cocama nacen en el Perú, migración y problemas de identidad entre los cocama del río Amazonas”. En: Antropológica, 21. Disponible en: http://revistas.pucp.edu.pe/index.php/anthropologica/ article/view/764.

Tessmann, Günter. [1930] Los indígenas del Perú Nororiental. Investigaciones fundamentales para un estudio sistemático de la cultura.1ra ed. castellana. Quito: Ayba-Yala, 1999. 